\title{
A base-line study of the wear of burs used for chairside milling of ceramic crowns of different hardness - Effect on internal fit and surface roughness
}

SADJ November 2020, Vol. 75 No. 10 p534 - p540

AA Ahmed ${ }^{1}$, CP Owen ${ }^{2}$

\section{ABSTRACT}

\section{Introduction}

Wear of milling burs may affect the internal fit and surface roughness of the milled crown. Aim: To assess the wear of diamond and tungsten carbide (TC) burs from milling ceramic materials and the effect on internal fit and surface roughness.

\section{Methods}

Thirty crowns of each of the two materials were milled from the same standard preparation. Diamond burs were used for a feldspathic ceramic and TC burs for zirconia. Before and after the $10^{\text {th }}, 20^{\text {th }}$ and $30^{\text {th }}$ milling, diamond particle loss was counted and cutting blade changes of the TC burs measured. Internal fit was measured using a silicone replica technique and surface roughness by 3D laser microscope.

\section{Results}

An average $26 \%$ loss of diamond particles occurred after 30 crowns, resulting in a $6 \%$ decrease in internal luting space and a $21 \%$ decrease in surface roughness. Wear of the TC burs resulted in a $13 \%$ decrease in the luting space, and a $16 \%$ increase in surface roughness.

\section{Conclusion}

The wear of milling burs reduces the luting space, and the milling parameters must be adjusted to compensate for this. Surface roughness is affected by bur type: with diamond burs it decreased, and increased with TC burs.

\section{Author affiliations:}

1. Ayman A Ahmed: BDS, MScDent, Postgraduate student, Department of Prosthodontics, School of Oral Health Science, Faculty of Health Sciences, University of the Witwatersrand, Johannesburg, South Africa.

2. C Peter Owen: $B C h D, M S c D e n t, M C h D, F C D(S A)$, Emeritus Professor, Faculty of Health Sciences, University of the Witwatersrand, Johannesburg, South Africa. ORCID Number: 0000-0002-9565-8010

Corresponding author: C Peter Owen

Faculty of Health Sciences, University of the Witwatersrand, 7 York Rd, Parktown, 2193, South Africa.

Email: peter.owen@wits.ac.za

Author contributions:

1. Ayman A Ahmed: Methodology, validation, investigation, writing, review - $50 \%$

2. C Peter Owen: Conceptualization, methodology, validation, writing - original draft; review and editing; supervision; project administration - $50 \%$

\section{Keywords}

CAD/CAM milling burs, internal fit, surface roughness, ceramics.

\section{INTRODUCTION}

In recent years, many dental Computer Aided Design and Computer Aided Manufacture (CAD/CAM) systems have been developed and introduced to the market both for chairside milling as well as laboratory fabrication, and restorations made this way have become more affordable and increasingly accurate. ${ }^{1}$

Milling systems, however, still have some constraints, related to movements of the axes, necessitating that the scanner is able to see all parts of the preparation without undercuts, as well as the size of the burs, which in turn influences the preparation form. The diameter of the smallest bur is $1 \mathrm{~mm}$ in most systems, so structures smaller than $1 \mathrm{~mm}$ cannot be milled precisely. ${ }^{2}$

A number of researchers have investigated the effect on the accuracy of the milled crowns and the loss of diamond particles from the bur after repeated machining up to 30 and sometimes 50 crowns using one diamond bur. ${ }^{3,4}$ Yara and colleagues $(2005)^{3}$ found that a diamond bur could be used to fabricate up to 21 crowns when using two different milling systems using feldspathic ceramics of different Vickers hardness. Furthermore, they showed that the crowns' average surface roughness ranged from 1.1 to $2.1 \mu \mathrm{m}$ for the one system and from 0.8 to $1.6 \mu \mathrm{m}$ for the other. There were significant diamond losses of $34 \%$ and $8 \%$ respectively. They concluded that the Vickers Hardness of the ceramic blocks used influenced the diamond particle loss as well as the surface roughness. ${ }^{3}$

Tomita et al (2005) $)^{4}$ found that one diamond bur could be used to fabricate up to 51 feldspathic crowns using their milling system but that from the $41^{\text {st }}$ to $51^{\text {st }}$ crown there was a tendency to mill with a larger inner surface gap and a slightly smaller outer surface.

They also found tiny chip marks at the cervical contour from the $21^{\text {st }}$ to $51^{\text {st }}$ crowns. SEM observation showed 
that after 11 to 21 times of machining the diamond abrasive particles were gradually lost as the number of machining times increased. ${ }^{4}$ Other studies reported an increase in surface roughness when milling Vita Mark II ceramic blocks and observed, but did not quantify, bur wear. ${ }^{5,6}$ A study to determine whether machining variability might impact on the strength of chairside ceramics, found that surface roughness and bi-axial flexure strength were influenced by the bur sets used, i.e. the machining tool variability. ${ }^{7}$

These studies have shown that diamond burs used for chairside milling of restorations are subject to wear in proportion to the hardness of the material being milled, and the number of times the bur was used. This in turn has an influence the surface roughness of the restoration. It is therefore imperative to know the precise relationship between the state of wear of the bur and the effect on milling accuracy and surface roughness.

In general, wear has been measured by particle loss in diamond burs by observations on only one part of the bur. ${ }^{3,4}$ There have been few reports on the wear of tungsten carbide burs, and most have reported on dulling and rupture of the blade edges of dental handpiece burs when cutting ceramics, ${ }^{8}$ or observations of chipping on tungsten-carbide burs used for milling titanium crowns. ${ }^{9}$

The creation of a luting space for full crowns was originally advised to create space for the luting agent. With $\mathrm{CAD} / \mathrm{CAM}$ systems the milling constraints have given rise to recommendations for the creation of a luting space of up to $100 \mu \mathrm{m}$. A variety of methods have been used to measure this space, such as the use of micro-CT which unfortunately requires expensive equipment, as well as the more cost effective use of a silicone replica as described by Nakamura et al (2003)..$^{10}$ These provide a measure of the total internal fit of the preparation.

The aim of this study was to assess the wear of diamond and tungsten carbide milling burs after milling up to 30 full crowns from two different ceramic materials of different hardness, and the effect of this wear if any, on the internal fit and surface roughness.

\section{METHODS}

A typodont tooth (tooth 36) was prepared to receive an all-ceramic crown restoration. The preparation had a circumferential shoulder margin, an axial reduction of $1.5 \mathrm{~mm}$, a $1.5 \mathrm{~mm}$ occlusal reduction, rounded internal angles, and $12^{\circ}$ total occlusal convergence angle. The crown was scanned (CEREC Omnicam, Dentsply/ Sirona, Germany) and printed in Cobalt-Chromium.

For the crowns, the milling parameters were set to produce an internal gap of $200 \mu \mathrm{m}$, in order to ensure that this space did not unduly influence subsequent measures of fit. ${ }^{11}$ The materials used were Sirona blocs C (Dentsply Sirona, Germany) and Zirconium oxide (inCoris TZI puck, Dentsply Sirona, Germany). The MC X5 milling machine (Dentsply/Sirona, Germany) was used to mill all crowns. Diamond burs (set of 1.2, 1.4 and $2.2 \mathrm{~mm}$ sizes, Dentsply/Sirona, Germany) were used to mill the
Sirona blocs C. Tungsten Carbide burs (set of 0.5, 1.0 and $2.5 \mathrm{~mm}$ sizes, Dentsply Sirona, Germany) were used to mill the inCoris TZI puck.

Prior to milling, and after the $10^{\text {th }}, 20^{\text {th }}$ and $30^{\text {th }}$ milled crowns the milling process was paused, and the burs were scanned by Scanning Electron Microscope (SEM) (Carl Zeiss Sigma Filled Admission Zeiss, Germany), to count the particles lost after a method modified from Yara et al (2005). ${ }^{3}$ They were then re-installed to continue milling the crowns. The Zirconia burs were similarly scanned in order to determine any edge wear.

For the diamond burs, the bur shank was marked into four quadrants around its circumference to ensure that measurements were made in the same quadrant each time. The burs were scanned with magnifications of 100x, 200x and 500x. The SEM images of the burs were imported into a computer graphics programme (CorelDraw, Corel, Canada). A frame of $1 \mathrm{~mm}$ high and $1 \mathrm{~mm}$ wide, was prepared in the computer with a $10 \mathrm{x}$ 10 grid. The top margin was adjusted to be $0.5 \mathrm{~mm}$ from the top of the bur and centred from the sidewalls of the bur. This frame was used to count the diamond particles within it (Fig. 1). One observer was used but we did not test for intra-rater reliability which is a possible limitation, but the concern was with the trend of wear. Fig. 2 shows the tip of the bur under magnification 500 times before, and at the $10^{\text {th }}, 20^{\text {th }}$ and $30^{\text {th }}$ milled crowns.

For the tungsten carbide burs, as previous studies have reported only chipping of the burs after milling, this study set out to quantify the wear. The burs were scanned before use, and the diameter $(Y)$ and width $(X)$ of the blades were measured (Fig. 3).

It was found that the SEM scan of the burs after milling did not provide accurate quantification measurements, due to the different scales and angles when scanned, and therefore a statistical proportional method was adopted to calculate any differences due to wear.

With $X 1$ being the width after milling, the blade wear is $X-X 1$. With $Y 1$ being the bur diameter after milling, proportionally, $X 1=X(Y 1 / Y)$ as $X / Y$ is proportional to $\mathrm{X} 1 / \mathrm{Y} 1$.

The $1^{\text {st }}, 10^{\text {th }}, 20^{\text {th }}$ and $30^{\text {th }}$ crowns of both materials were filled with light-body polyvinyl siloxane impression material (3M ESPE Express. 3M, United States) and placed on the metal tooth die under a constant load of $3 \mathrm{~kg}$ weight, placed on the flat occlusal surface of the crown for 10 minutes. After the silicone impression material had polymerised, the excess material was removed with a scalpel blade. The material from the internal gap was taken out as one piece and weighed to calculate the overall internal fit according to the formula: ${ }^{10}$

Thickness $($ internal gap $)=\frac{(\text { weight })}{((\text { surface } \text { area } \times \text { density }))}$

Where the surface area was $183.8 \mathrm{~mm}^{2}$ (calculated using FEA software) and the density was $1.29 \mathrm{~g} / \mathrm{ml}$ (obtained from the manufacturer). 

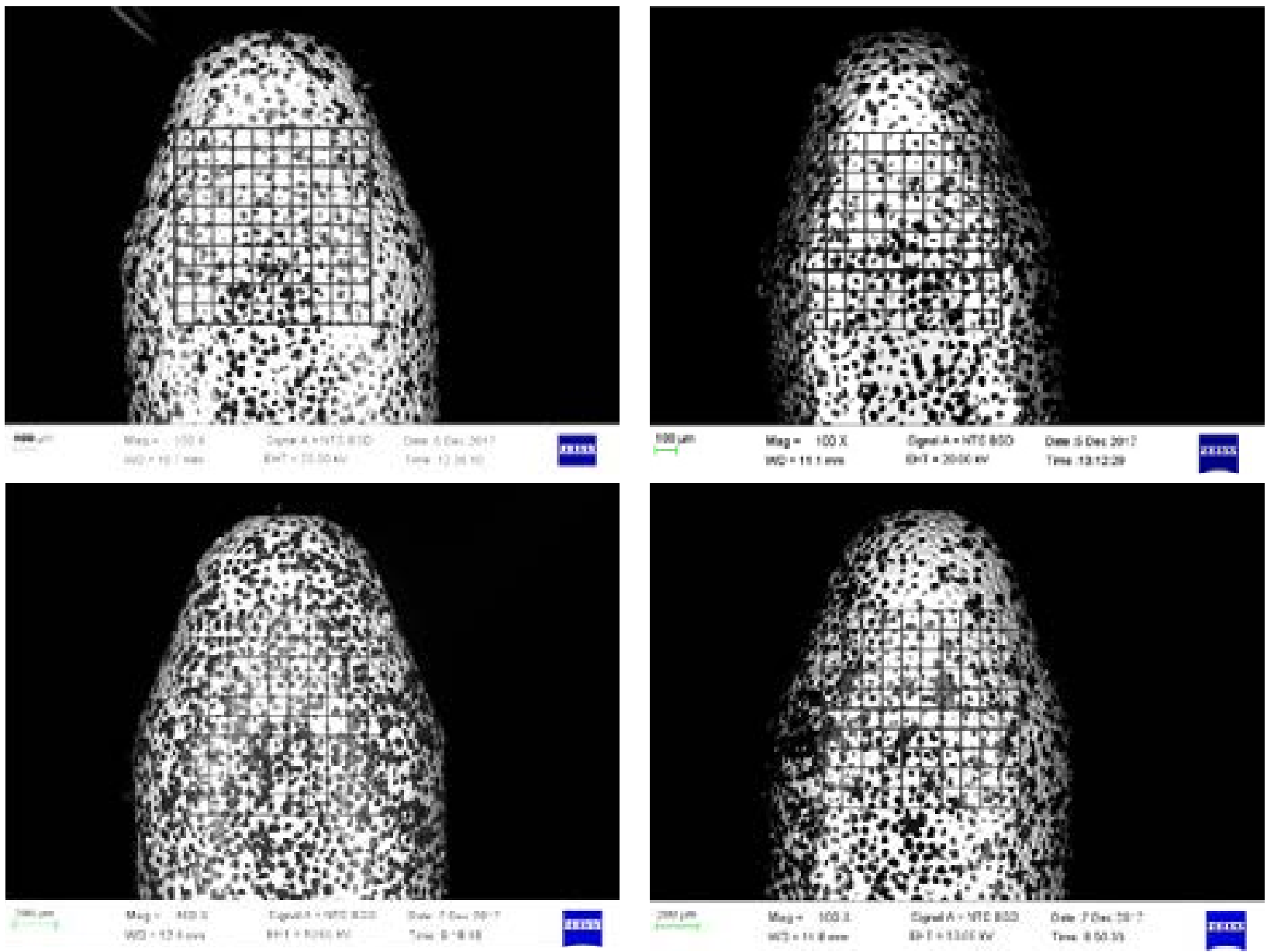

Figure 1. The four quadrants of the Diamond bur, size $1.2 \mathrm{~mm}$ before milling.
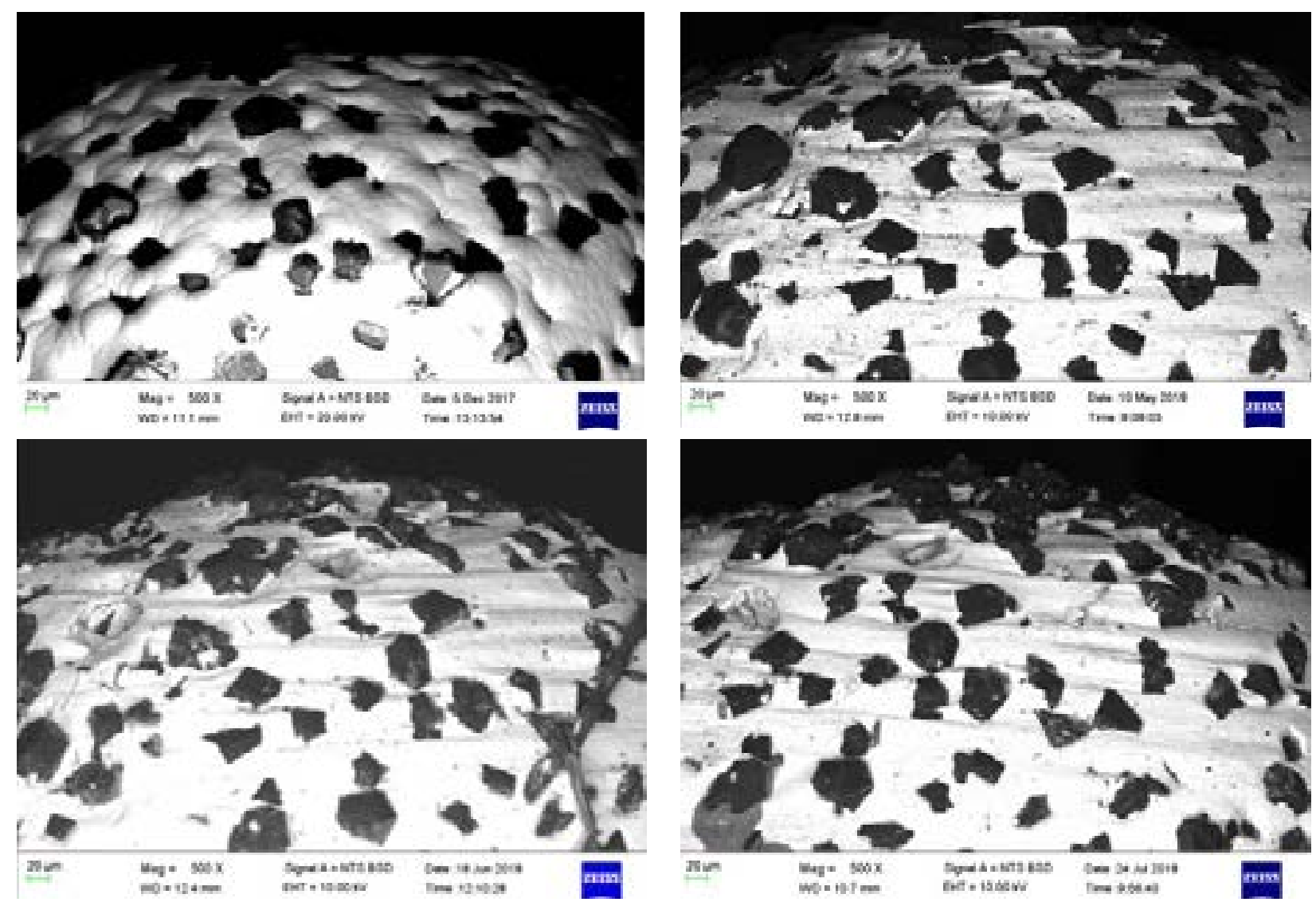

Figure 2. The Diamond bur, size $1.2 \mathrm{~mm}$ magnification $\times 500$ before milling (top left), after milling the $10^{\text {th }} \mathrm{crown}$ (top right), after milling the $20^{\text {th }}$ crown (bottom left), and after milling the $30^{\text {th }}$ crown (bottom right). 
The $1^{\text {st }}, 10^{\text {th }}, 20^{\text {th }}$ and $30^{\text {th }}$ crowns of both materials were scanned with a 3D Measuring Laser Microscope (Olympus LEXT OLS5000, Olympus Corporation, Japan) to measure the surface roughness. On the software (OLS50-BSW, Olympus Corporation, Japan) a frame size $12 \mu \mathrm{m} \times 12 \mu \mathrm{m}$ was placed on the occlusal surface of the crown to give the average surface roughness (Fig. 4).

The analysis parameter used was the arithmetic mean height (Sa). It is equivalent to the arithmetic mean of the measured region on the three-dimensional display diagram when valleys have been changed to peaks by

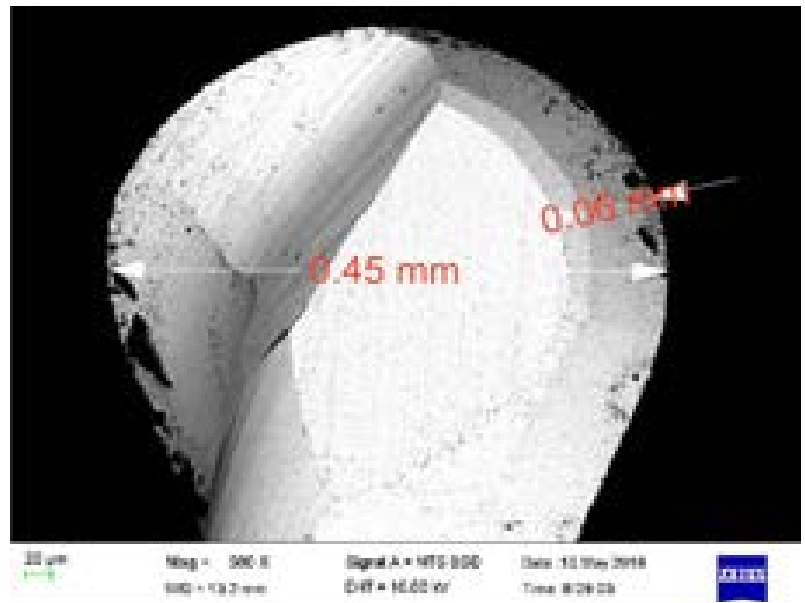

conversion to absolute values (as per Olympus resource at https://www.olympus-ims.com/en/knowledge/metrology/roughness/3d_parameter/).

\section{Data analysis}

Continuous variables were summarised by the mean, standard deviation, median and interquartile range. The effect of material and number of crowns milled on the internal fit (IF) and surface roughness (SR) outcomes was determined by a two-way Analysis of Variance (ANOVA) with the outcome as the dependent variable,

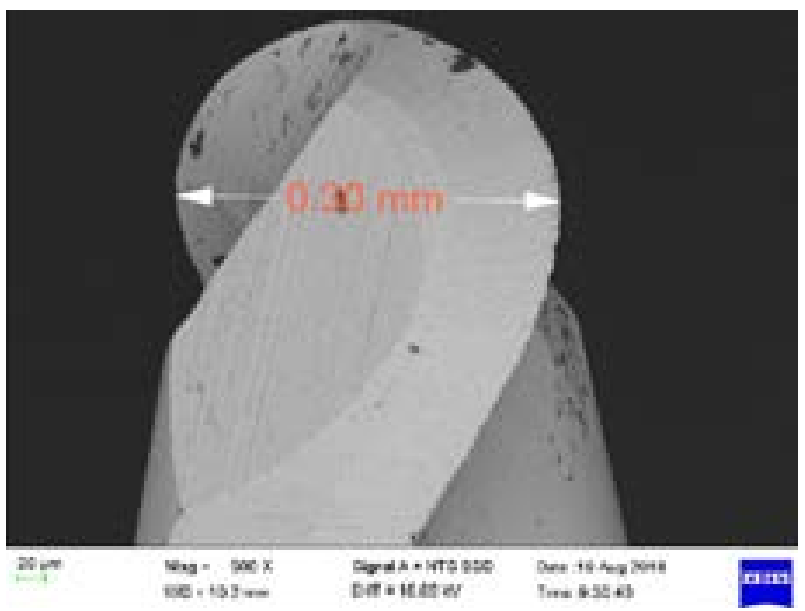

Figure 3. Bur size 0.5 for Zirconia. (Left) before milling, (right) after milling of the $30^{\text {th }}$ crown, magnification $500 x$.

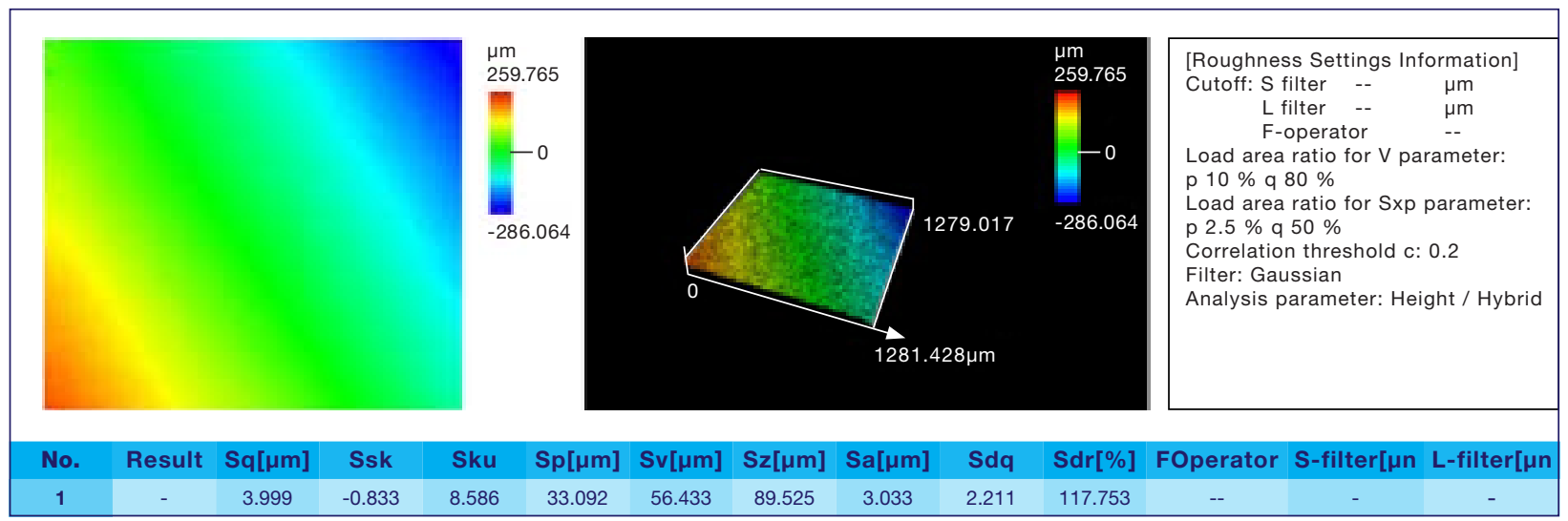

Figure 4. Sirona blocs $\mathrm{C}$ surface roughness for Crown number 1.

\begin{tabular}{|c|c|c|c|c|c|c|c|}
\hline Milling time & Bur size & Side 1 & Side 2 & Side 3 & Side 4 & Average & $\%$ Loss \\
\hline \multirow{4}{*}{ Before 1} & 1.2 & 280 & 284 & 300 & 288 & 1152 & - \\
\hline & 1.4 & 251 & 249 & 223 & 249 & 972 & - \\
\hline & 2.2 & 126 & 122 & 131 & 145 & 524 & - \\
\hline & & & & \multicolumn{2}{|c|}{ Total average particle wear } & 2648 & - \\
\hline \multirow[t]{4}{*}{ After 10} & 1.2 & 246 & 229 & 253 & 236 & 964 & 16 \\
\hline & 1.4 & 229 & 234 & 230 & 230 & 923 & 5 \\
\hline & 2.2 & 86 & 102 & 103 & 101 & 392 & 25 \\
\hline & & & & \multicolumn{2}{|c|}{ Total average particle wear $/ \%$ loss } & 2279 & 14 \\
\hline \multirow[t]{4}{*}{ After 20} & 1.2 & 262 & 195 & 236 & 198 & 891 & 23 \\
\hline & 1.4 & 213 & 217 & 210 & 209 & 849 & 13 \\
\hline & 2.2 & 75 & 98 & 109 & 97 & 379 & 28 \\
\hline & & & & \multicolumn{2}{|c|}{ Total average particle wear/\% loss } & 2119 & 20 \\
\hline \multirow[t]{4}{*}{ After 30} & 1.2 & 218 & 190 & 251 & 221 & 880 & 24 \\
\hline & 1.4 & 226 & 190 & 156 & 195 & 767 & 21 \\
\hline & 2.2 & 66 & 105 & 110 & 43 & 324 & 38 \\
\hline & & & & \multicolumn{2}{|c|}{ Total average particle wear $/ \%$ loss } & 1971 & 26 \\
\hline
\end{tabular}


and material and number of crowns milled as the independent variables.

The interaction between material and number of crowns milled could not be assessed, as there were insufficient degrees of freedom for such an analysis. The relationship between wear and number of crowns milled for each material was explored descriptively, as were the relationships between IF, SR and wear for each material. Data analysis was carried out using SAS version 9.4 for Windows. The 5\% significance level was used.

\section{RESULTS}

Table 1 shows the wear of diamond particles. This table gives the measurement values of three bur sizes making use of the four sides of the bur. It can be seen that the total particle loss after the $10^{\text {th }}$ milling time was an average of 369 particles, while after $30^{\text {th }}$ milling time the particle loss was an average of 677 particles, an average loss of $26 \%$.

Table 2 shows the results of the milling of the Zirconium Oxide using different bur sizes. It shows the average wear of the burs of different sizes in $\mathrm{mm}$. The minimum value of wear occurred with the $2.5 \mathrm{~mm}$ bur size $(0.03 \mathrm{~mm})$ and the higher value occurred with the $1.00 \mathrm{~mm}$ bur size (0.12 mm).

Table 3 and Fig. 5 show the milling times for Sirona blocs $\mathrm{C}$ together with the average wear (loss) of bur particles, the internal fit and the surface roughness, and Table 4 and Fig. 6 shows the similar parameters for the Zirconia. There were no statistically significant diffe-

\begin{tabular}{|l|c|c|c|}
\hline \multicolumn{2}{l}{ Table 2. Wear of tungsten carbide burs. } \\
\hline Milling time & Bur size & Average wear $(\mathbf{m m})$ & $\%$ Change \\
\hline After 10 & 0.5 & 0.0093 & 1.86 \\
\hline & 1.0 & 0.0017 & 0.17 \\
\hline Total average wear/\% change & 2.5 & 0.00324 & 0.13 \\
\hline After 20 & 0.5 & 0.01424 & 0.72 \\
\hline & 1.0 & 0.0173 & 3.46 \\
\hline Total average wear/\% change & 0.0034 & 0.34 \\
\hline After 30 & 0.5 & 0.00972 & 0.39 \\
\hline & 1.0 & 0.03042 & 1.4 \\
\hline Total average wear/\% change & 0.02 & 4.00 \\
\hline
\end{tabular}

rences between the materials $(p=0.32)$ in terms of the surface roughness or for the internal fit $(p=0.12)$.

Figure 5. Sirona Blocs C average wear (Particles, green), internal fit (IF, blue), and surface roughness (Sa, orange).

Figure 6.Zirconia burs average percentage change (green), internal fit (IF, blue), and surface roughness (Sa, orange).

For the Sirona blocs and diamond burs, there was an overall $6 \%$ reduction in the internal fit and a $21 \%$ reduction in surface roughness. For the Zirconia, there was an overall $13 \%$ reduction in the internal fit and a $16 \%$ increase in surface roughness.

\section{DISCUSSION}

The results revealed a clear relationship between the wear of the burs and the number of crowns milled. Wear was assessed in the diamond burs by the loss of particles, and the results were similar to the findings of other studies. ${ }^{3,4}$

Studies on the wear of non-diamond burs have been limited to counts of chips off the cutting blades. We believe that the method of assessing wear whereby SEM photomicrographs could be directly measured and a factor derived to represent the wear is a more accurate measure of wear for these burs.. As with the diamond burs, there was clearly an increase in wear with the number of crowns milled.

There were no statistically significant differences between the two materials tested. This may be explained by the fact that both materials used, had relatively low Vickers Hardness numbers. This has been related to bur wear in previous studies. ${ }^{3}$

In this study, there was no clear trend in the percentage of particles lost relative to the diamond bur sizes, with the $1.4 \mathrm{~mm}$ diameter bur displaying the least percentage loss of particles (21\%) followed by the $1.2 \mathrm{~mm}$ bur $(24 \%)$ and the $2.2 \mathrm{~mm}$ bur (38\%).

For the diamond burs, with increasing numbers of crowns, there was a concomitant increase in bur wear, as well as a decrease in internal fit ( $6 \%$ after 30 crowns), and a decrease in surface roughness (21\% after 30 crowns).

\begin{tabular}{|c|c|c|c|}
\hline $\begin{array}{l}\text { Crown milling } \\
\text { number }\end{array}$ & $\begin{array}{l}\text { Average number of diamond bur } \\
\text { particles in } 1 \mathrm{~mm}^{2} \text { frame }\end{array}$ & Internal fit silicone & $\begin{array}{l}\text { Crown average surface roughness } \\
\mathrm{Sa}(\mu \mathrm{m})\end{array}$ \\
\hline 1 & 2648 & 0.192 & 3.270 \\
\hline 10 & 2279 & 0.189 & 3.033 \\
\hline 20 & 2119 & 0.186 & 3.061 \\
\hline 30 & 1971 & 0.181 & 2.591 \\
\hline
\end{tabular}

$\begin{gathered}\text { Table 4. Zirconium Oxide average percentage change of the burs, the internal fit and the surface roughness. } \\ \text { Crown milling } \\ \text { number }\end{gathered}$
$\begin{array}{ccc}\text { Average } \% \text { change } \\ \text { Internal fit silicone }\end{array}$


These are logical trends, and point to the fact that when milling with diamond burs, to maintain the internal luting space, the parameters for milling must be adjusted to compensate for bur wear. If this is not done, then the internal milled luting space may be inadequate and may result in incomplete seating of the crown. This may explain any change in occlusion post-cementation, which should not occur if the luting space is adequate.

For the tungsten-carbide burs, similar trends were observed for bur wear and internal fit (13\% after 30 crowns), but there was an overall increase in surface roughness (16\% after 30 crowns). This may be explained by the increased chipping of the cutting edge which will increase the roughness.

\section{Limitations}

This study only investigated the internal fit and surface roughness and not the marginal gap; only two ceramics were used, and feldspathic porcelain is sintered, and zirconia is partially sintered. This was, though, a baseline study and further studies are recommended using different ceramics and burs, so that recommendations can be made as to when to not only change the burs, but also to adjust the milling parameters and to determine for each bur and material combination, the number of crowns at which clinically unacceptable results would be obtained.

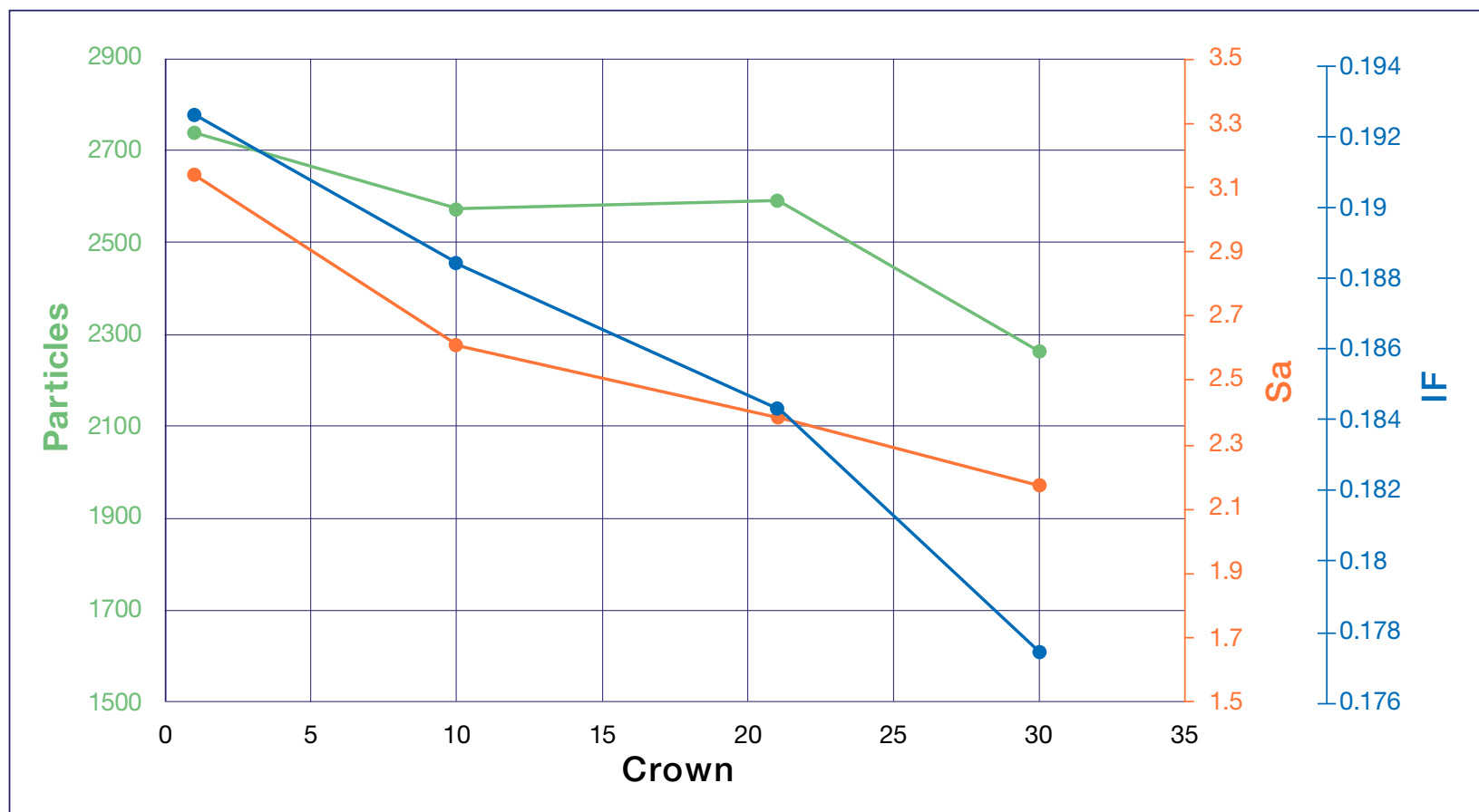

Figure 5. Sirona Blocs C average wear (Particles, green), internal fit (IF, blue), and surface roughness (Sa, orange).

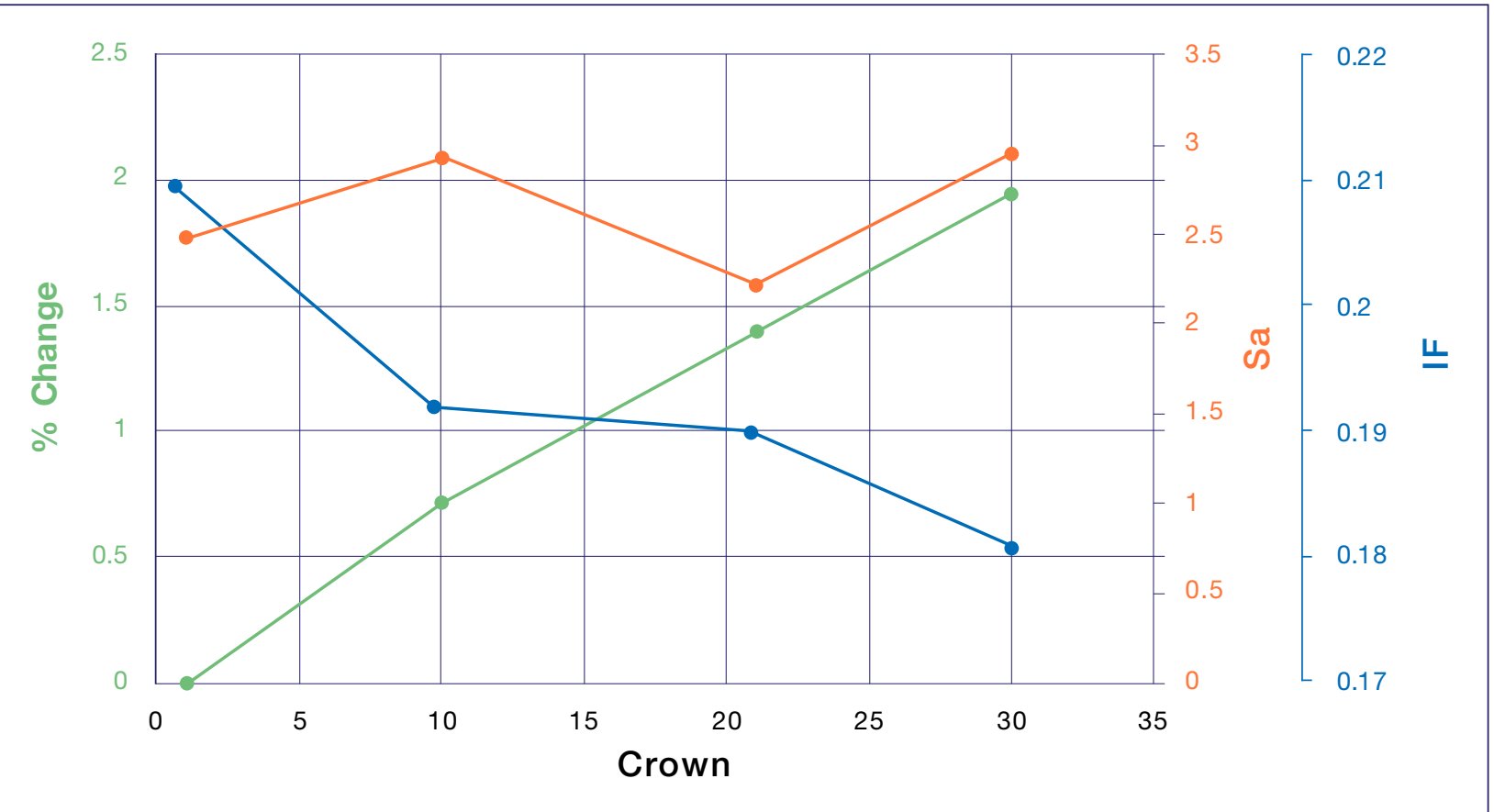

Figure 6. Zirconia burs average percentage change (green), internal fit (IF, blue), and surface roughness (Sa, orange). 


\section{CONCLUSION}

This would appear to be the first study to measure the wear of diamond burs in four quadrants and compare this with the internal fit and surface roughness, using two different materials. It is also the first study to measure the cutting blades of tungsten carbide burs, and may be used as a baseline for other future studies to compare against.

The results, showed trends that were expected and confirmed that with increasing bur wear, either as particle loss in diamond burs, or reduction in cutting blade size in tungsten-carbide burs, there was a concomitant decrease in the internal fit of $6 \%$ and $13 \%$ respectively after 30 crowns. It is important, therefore, to compensate for this by adjusting the milling parameters.

The nature of the wear in the tungsten carbide burs was such that the cutting blades became rough, and this resulted in an increase in surface roughness (16\%) of the milled crown. In contrast, the nature of the wear in diamond burs is a reduction of particle numbers, such that the bur becomes smoother, and this was reflected in the decrease in surface roughness $(6 \%)$ with the number of crowns milled.

\section{References}

1. Miyazaki T, Hotta Y, Kunii J, Kuriyama S, Tamaki Y. A review of dental CAD/CAM: current status and future perspectives from 20 years of experience. Dent Mater J 2009; 28(1): 44-56.

2. Beuer $F$, Aggstaller $H$, Richter J, Edelhoff D, Gernet W. Influence of preparation angle on marginal and internal fit of CAD/CAM-fabricated zirconia crown copings. Quintessence Int. 2009; 40(3): 243-50.

3. Yara A, Ogura H, Shinya A, Tomita S, Miyazaki T, Sugai $Y$, et al. Durability of diamond burs for the fabrication of ceramic crowns using dental CAD/CAM. Dent Mater J. 2005; 24(1): 134-9.

4. Tomita S, Shin-Ya A, Gomi H, Matsuda T, Katagiri S, Shin-Ya A, et al. Machining accuracy of CAD/CAM ceramic crowns fabricated with repeated machining using the same diamond bur. Dent Mater J. 2005; 24(1): 123-33.

5. Roperto RC, Lopes FC, Porto TS, Teich S, Rizzante FAP, Gutmacher $Z$ et al. CAD/CAM Diamond Tool Wear. Quintessence Int, 2018; 49(10): 781-6

6. Raposo LH, Borella PS, Ferraz DC, et al. Influence of Computer-aided Design/Computer-aided Manufacturing Diamond Bur Wear on Marginal Misfit of Two Lithium Disilicate Ceramic Systems. Oper Dent. 2019. doi: 10.2341/19-089-L. Online ahead of print.

7. Addison O, Cao X, Sunnar P, Fleming GJP. Machining Variability Impacts on the Strength of a 'Chair-Side' CAD-CAM Ceramic. Dent Mater. 2012; 28(8): 880-7

8. Tanaka N, Taira M, Wakasa K, Shintani H, Yamaki M. Cutting effectiveness and wear of carbide burs on eight machinable ceramics and bovine dentin. Dent Mater. 1991; 7(4): 247-53

9. Hotta Y, Miyazaki T, Fujiwara T, Tomita S, Shinya A, Sugai Y, et al. Durability of Tungsten Carbide Burs for the Fabrication of Titanium Crowns Using Dental CAD/CAM. Dent Mater J. 2004; 23(2): 190-6.

10. Nakamura T, Dei N, Kojima T Wakabayashia K. Marginal and Internal Fit of Cerec 3 CAD/CAM All-Ceramic Crowns. Int J Prosthodont. 2003; 16(3): 244-8.

11. Babiolakis GB, Owen CP. The effect of off-axis seating on the marginal adaptation of full coverage all ceramic crowns. SADJ. 2020; 75(6): 301-30. 